\title{
A educação infantil no contexto das políticas públicas*
}

\author{
Angela Maria Rabelo Ferreira Barreto
}

Universidade de Brasília, Instituto de Psicologia

As análises desenvolvidas neste trabalho visam subsidiar a discussão sobre a situação atual da educação infantil, como política pública, no Brasil. Buscando-se a aproximação de objeto de estudo tão complexo, procura-se situar o lugar das políticas e dos programas atuais, de âmbito federal, dirigidos à criança de 0 a 6 anos de idade, especialmente daqueles que se referem ao atendimento em creches e pré-escolas, bem como analisar alguns desafios impostos pelo Plano Nacional de Educação no que tange à educação infantil.

Este trabalho serve-se de dois estudos anteriores. O primeiro foi desenvolvido no âmbito da pesquisa "Crianças de zero a seis anos: suas condições de vida e seu lugar nas políticas públicas" (Barreto,

* Trabalho apresentado na sessão especial promovida pelo GT Educação da Criança de 0 a 6 anos, na 25a Reunião Anual da ANPEd, realizada em Caxambu, MG, de 29 de setembro a 2 de outubro de 2002. Agradeço a Maria Malta Campos pela revisão cuidadosa do texto e as sugestões para seu aperfeiçoamento.
2001). O segundo, em co-autoria (Castro \& Barreto, 2002), foi elaborado para o Simpósio Educação Infantil: Construindo o Presente.

\section{Políticas e programas federais destinados à criança de 0 a 6 anos}

Barreto (2001) realiza um mapeamento e a análise descritivo-interpretativa das políticas e programas federais destinados à criança de 0 a 6 anos, em andamento na segunda gestão do Governo Fernando Henrique Cardoso, especialmente nas áreas de educação, saúde e assistência social, buscando identificar os alcances e limites dessas políticas ou programas. O estudo incluiu análise documental e entrevistas com dirigentes e técnicos, realizadas por Barreto (2001), Almeida (2001) e Barros (2001). Foram analisados os documentos Avança Brasil: proposta de governo (1998), o Plano Plurianual (PPA 2000-2003), o Orçamento da União para os anos 2000 e 2001, os sistemas de acompanhamento da execução orçamentária, além de documentos técnicos, peças de divulgação institucional e relatórios gerenciais dos órgãos 
federais, alguns disponíveis nos sítios das instituições na internet.

A análise das intenções de políticas do segundo Governo de Fernando Henrique Cardoso, relativas à criança de 0 a 6 anos e explicitadas no documento Avança Brasil: proposta de governo, permite identificar três perspectivas sobre as quais se assentam tais intenções: a que se fundamenta nos direitos da criança como cidadã; a que considera a criança pequena como uma faixa vulnerável por sua condição de dependência econômica e social; e a que leva em conta os direitos da mulher e a igualdade de oportunidades para homens e mulheres.

Verifica-se que tais intenções políticas são feitas a partir de perspectivas que vêm se consolidando no cenário brasileiro, consagradas na Constituição de 1988 e em leis setoriais posteriores, como a Lei de Diretrizes e Bases da Educação Nacional (LDB, lei no 9.294/ 96), a Lei Orgânica da Assistência Social (LOAS) a legislação própria da área da saúde, entre outras. Observa-se, entretanto, em algumas passagens, que aspectos assegurados nas leis não são ainda completamente incorporados nas propostas do governo. Isso é mais evidente quando se trata da educação da criança de 0 a 3 anos; embora, com a LDB, a creche tenha sido incluída, junto com a pré-escola, na educação infantil, reconhecida como primeira etapa da educação básica, muitos dos objetivos explicitados no Avança Brasil referem-se apenas à pré-escola (como formação de professores e merenda escolar, para citar dois deles). O texto que trata da educação infantil no Avança Brasil inspira-se em versão do Plano Nacional de Educação apresentada pelo MEC e que foi superada por aquela aprovada no Congresso Nacional e sancionada pelo presidente da República em janeiro de 2001. Nessa última, as inconsistências foram minimizadas.

O Plano Plurianual (PPA) ${ }^{1}$ 2000-2003 utiliza como referência fundamental o documento Avança

${ }^{1}$ O PPA, como instrumento de planejamento, foi criado com a Lei de Diretrizes Orçamentárias (LDO), na Constituição de 1988. O Plano para o período 2000-2003 introduz uma nova metodologia
Brasil - proposta de governo -, inclusive incorporando em seu título a expressão Avança Brasil. Estabelece como grande meta para o período construir um novo modelo de desenvolvimento voltado para o atendimento das necessidades básicas do cidadão e para a melhor distribuição dos frutos do crescimento econômico entre os brasileiros. Tal meta é traduzida em seis diretrizes estratégicas, que por sua vez se desdobram em 28 macroobjetivos, e estes em um total de 365 programas. Cada programa inclui uma série de ações, cada uma com meta própria e sob a responsabilidade de uma ou mais unidades organizacionais do governo federal.

Utilizando como fontes privilegiadas de informações o PPA 2000-2003 e os orçamentos da União de 2000 e 2001, os quais constituem os principais instrumentos legais de planejamento e alocação de recursos do governo federal, Barreto (2001) identifica os programas/ações dirigidos à criança de $0 \mathrm{a} 6$ anos. No Quadro 1 são apresentados os programas e ações em que a criança de 0 a 6 anos comparece como público-alvo. Nos itens I e II do quadro estão relacionados programas e ações em que a criança de 0 a 6 é o público-alvo específico e no item III são identificadas as ações que explicitamente incluem a criança de 0 a 6 anos, mas não se limitam a elas.

Esse segmento etário é alvo, evidentemente, de muitas ações que incluem toda a população. $\mathrm{Na}$ área da assistência social, por exemplo, podem-se destacar as ações "Atendimento à pessoa portadora de deficiência" e "Pagamento de benefício de prestação continuada à pessoa portadora de deficiência". $\mathrm{Na}$ área da saúde, várias ações abrangem a criança de 0 a 6 anos, como parte de toda a população.

de organização das ações do governo federal em torno de programas. Um programa articula um conjunto de ações que concorrem para um objetivo comum preestabelecido, mensurado por indicadores, visando à solução de um problema ou o atendimento de necessidades ou demandas da sociedade (Manual do PPA 20002003). 


\section{Q uadro 1}

Presença da criança de 0 a 6 anos no PPA 2000-2003

\section{Público-alvo específico dos Programas \\ Atenção à Criança. \\ Saúde da Criança e Aleitamento Materno.}

2. Público-alvo específico das Ações

Do Programa Assistência ao Trabalhador

- Assistência pré-escolar aos dependentes dos servidores e empregados.

Do Programa Alimentação Saudável

- Incentivo financeiro a municípios habilitados à parte variável do Piso de Atenção Básica - PAB para ações de combate às carências nutricionais.

- Qualificação de municípios para recebimento do incentivo financeiro a municípios habilitados à parte variável do Piso de Atenção Básica (PAB) para ações de combate às carências nutricionais*.

3. Público-alvo das Ações, junto com outros segmentos vulneráveis

Do Programa Alimentação Saudável

- Aquisição e distribuição de micronutrientes para crianças, gestantes e idosos em áreas endêmicas de má nutrição.

-Estudos e pesquisas sobre recuperação nutricional e alimentação saudável.

- Promoção de eventos técnicos sobre recuperação nutricional e alimentação saudável.

- Implantação de sistema de informação em má nutrição por micronutrientes.

Do Programa Brasil Jovem

- Abrigo

Do Programa Aceleração da Aprendizagem (Toda Criança na

Escola)

- Alimentação Escolar

* Ação que está sendo substituída pelo Bolsa Alimentação.
Barreto (2001) verifica que, dos 365 programas que compõem o PPA, a criança de 0 a 6 anos comparece como público-alvo específico de apenas dois programas: Atenção à Criança e Saúde da Criança e Aleitamento Materno; e de ações de outros dois programas: Assistência ao Trabalhador e Alimentação Saudável. Nesses casos, as metas e os recursos dizem respeito exclusivamente a essa faixa etária. Para as ações dos três programas relacionados no item III do Quadro 1, as metas incluem vários segmentos vulneráveis, não sendo possível precisar, a partir da análise do PPA, quantas crianças de 0 a 6 anos são atendidas.

O programa Atenção à Criança é o que mais nos interessa neste estudo. Incluído no macroobjetivo de assegurar os serviços de proteção à população mais vulnerável à exclusão social, o programa tem por objetivo assegurar o atendimento a crianças carentes de até 6 anos em creches e pré-escolas.

O indicador definido é a taxa de crianças de até 6 anos atendidas, com renda familiar per capita de até $1 / 2$ salário mínimo. A taxa apresentada como mais recente no PPA é de $19 \%$ e a prevista para o final do período é de 30\%. No Quadro 2 são apresentadas outras informações sobre o programa.

Embora não apareça no projeto de lei do PPA 2000-2003, outra ação vem sendo incluída no programa Atenção à Criança, nos orçamentos anuais, por meio de emendas parlamentares. Trata-se da Cons-

\section{Q uadro 2}

PPA 2000-2003: Programa Atenção à Criança: Demonstrativo das ações

\begin{tabular}{|c|c|c|c|c|}
\hline Ações & $\begin{array}{c}\mathbf{P}, \mathbf{A} \\
\text { ou } \mathbf{O} *\end{array}$ & Unidade responsável $* * *$ & Meta/Produto** & $\begin{array}{c}\text { Previsão** Custos } \\
\text { em R\$1.000 }\end{array}$ \\
\hline 2.556 - Atendimento a crianças em creche & $\mathrm{A}$ & FNAS/MPAS, Estados, Mun., DF & 6.930 .284 crianças atendidas & 1.083 .925 \\
\hline 4.003 - Funcionamento da Ed. Infantil & A & IFES/MEC & 4.508 alunos matriculados & 856 \\
\hline $\begin{array}{l}3.088 \text { - Aquisição e distribuição de } \\
\text { material didático para Ed. Infantil }\end{array}$ & $\mathrm{P}$ & FNDE/MEC & $\begin{array}{l}\text { 2.545.000 módulos } \\
\text { distribuídos }\end{array}$ & 22.637 \\
\hline $\begin{array}{l}3.097 \text { - Formação continuada de } \\
\text { profesores da Ed. Infantil }\end{array}$ & $\mathrm{P}$ & FNDE/MEC & $\begin{array}{l}75.920 \text { professores } \\
\text { capacitados }\end{array}$ & 34.164 \\
\hline $\begin{array}{l}\text { 3.101 - Implementação do referencial } \\
\text { curricular nacional para a Ed. Infantil }\end{array}$ & $\mathrm{P}$ & FNDE/MEC & $\begin{array}{l}47.760 \text { professores } \\
\text { capacitados }\end{array}$ & 21.492 \\
\hline TOTAL & - & - & - & 1.163 .110 \\
\hline
\end{tabular}

Fonte: PPA 2000-2003.

* P - Projeto; A - Atividade; O - Outras ações.

** Refere-se aos quatro anos abrangidos pelo PPA 2000-2003.

*** Fundo Nacional para o Desenvolvimento da Educação (FNDE); Fundo Nacional de Assistência Social (FNAS); Instituições Federais de Ensino Superior (IFES). 
trução, Ampliação e Modernização das Creches. No ano de 2000, o orçamento executado nessa ação foi da ordem de 10,5 milhões de reais.

A análise do Quadro 2 evidencia que a ação mais significativa em termos de volume de recursos no programa Atenção à Criança é a que financia o atendimento de crianças em creches e que está sob a gestão da Secretaria de Estado de Assistência Social (SEAS). Responsável por aproximadamente 93\% dos recursos previstos do programa Atenção à Criança, esta ação caracteriza-se como um "serviço assistencial de ação continuada". ${ }^{2}$

A ação é executada de forma descentralizada por estados e municípios, e o apoio financeiro da União é realizado mediante a transferência de recursos "fundo a fundo", isto é, do Fundo Nacional de Assistência Social para os Fundos estaduais e municipais, para a manutenção de creches e pré-escolas públicas ou conveniadas com o poder público.

A história dessa ação na área da assistência social remonta ao final da década de 1970, quando a então Legião Brasileira de Assistência (LBA), instituição do Governo Federal extinta em 1995 e que teve suas atividades assumidas pela SEAS, criou e implantou o denominado Projeto Casulo. O projeto teve significativa expansão na década de 1980, sendo operacionalizado por meio de convênios com instituições privadas ou com prefeituras que mantinham crianças de baixa renda em creches e pré-escolas. Essa ampliação foi realizada com a utilização de espaços ociosos disponíveis na comunidade e, freqüentemente, com pessoal sem formação específica, atuando com condições de trabalho precárias. Vários estudos têm abordado essa história (Vieira, 1988; Campos, Rosemberg \& Ferreira, 1993; entre outros).

Como na época da LBA, os recursos são repassados para a manutenção do serviço com base em

${ }^{2}$ Os serviços assistenciais de ação continuada visam à garantia dos direitos básicos aos segmentos mais vulneráveis da população (crianças, adolescentes, idosos e portadores de necessidades especiais). valores per capita, diferenciados segundo a jornada em que a criança é atendida diariamente: integral (oito horas) ou parcial (quatro horas). Atualmente, esses valores são de $\mathrm{R} \$ 17,02$ e $\mathrm{R} \$ 8,51$, respectivamente. Cabe à unidade de atendimento oferecer alimentação, atividades pedagógicas em horário integral ou parcial, além de trabalho socioeducativo com famílias e com as próprias crianças. Segundo dados da SEAS, são cerca de 3.773 entidades responsáveis pela execução desse atendimento, em todas as unidades da Federação e em 59\% dos municípios.

Os recursos da União representam apenas parte do financiamento do serviço. Entretanto, não há informações sobre quanto se gasta no atendimento nos diferentes municípios, ou seja, qual é a parcela das outras instâncias governamentais e não-governamentais, o que torna pouco visível para a SEAS a parte co-financiada por essas instâncias (Almeida, 2001).

Não há dados sobre o número de crianças em jornada parcial ou integral de atendimento. Na verdade, verifica-se que há ainda grandes deficiências quanto a informações gerenciais nessa e nas outras ações de responsabilidade da SEAS, embora estejam sendo realizados esforços nessa direção.

Essa ação de apoio financeiro da União ao atendimento em creches, que, conforme visto, tem uma história de quase três décadas, vem atualmente passando por um momento delicado na administração pública federal e, como conseqüência, nas demais esferas de governo, em razão da ainda precária articulação entre os setores de assistência social e de educação. Com a consolidação, na Lei de Diretrizes e Bases da Educação Nacional, da concepção de educação infantil como primeira etapa da educação básica, incluindo as creches ( 0 a 3 anos) e as pré-escolas (4 a 6 anos), vem-se observando embates entre as duas áreas sobre a gestão e o financiamento das ações.

Em julho de 2000, a SEAS publicou a portaria $\mathrm{n}^{\mathrm{o}} 2.854$, introduzindo novas modalidades de atendimento, além de creches e pré-escolas, a serem financiadas com recursos da ação "atendimento à criança em creches". Em seu anexo, a portaria assim define as modalidades de atenção à criança de 0 a 6 anos: 


\section{APOIO À CRIANÇA DE 0 A 6 ANOS}

Atendimento em Unidades de Jornada Integral ou Parcial: essa modalidade era tradicionalmente desenvolvida apenas em creches e pré-escolas. Abre-se a possibilidade de realizar esse atendimento também em outros espaços físicos, utilizando inclusive outras formas de trabalhos com crianças, tais como: brinquedotecas, creches volantes (veículos equipados com jogos, brinquedos, com supervisão de educadoras infantis que se deslocam para diferentes pontos do município com a finalidade de realizar ação socioeducativa para adultos encarregados de trabalho com as crianças), atendimento domiciliar (crianças atendidas em casas de família com adequada supervisão técnica) etc. Em todas essas ações devem estar integradas as crianças portadoras de deficiência e as crianças em situação de extremo risco.

Ações socioeducativas de apoio à família: são ações comunitárias de promoção e informação às famílias de crianças de 0 a 6 anos, tais como: palestras sobre desenvolvimento infantil, oficinas pedagógicas promovendo interação pais/ crianças por meio de jogos e brincadeiras, cursos de capacitação profissional com vistas a ampliação de renda familiar etc. Devem ser priorizadas as famílias em situação de extremo risco: famílias de detentos, de ex-detentos, famílias com membros portadores do vírus HIV/AIDS, famílias sem teto, famílias sem terra, famílias vivendo em assentamentos, vítimas de enchentes, seca etc., na perspectiva de promovê-las e apoiá-las nos cuidados com seus filhos.

Deve-se observar que a introdução dessas novas modalidades não fica transparente no PPA nem nos orçamentos da União para 2000 e 2001, onde a ação, tal como descrita, restringe-se ao atendimento a crianças em creches. No relatório de gestão da SEAS de 2000 também não constam informações sobre as "novas modalidades". Conforme levantado por Almeida (2001), a SEAS ainda não tem um controle preciso dos municípios e estados que estão utilizando recursos para as novas ações instituídas pela portaria $\mathrm{n}^{\circ} 2.854 / 00$ da SEAS, nem quantos recursos estariam sendo remanejados e para quais modalidades.

As demais ações do programa Atenção à Criança, todas com recursos financeiros de pouca monta, estão sob a responsabilidade do Ministério da Educação. Consistem na assistência financeira, por intermédio do Fundo Nacional de Desenvolvimento da Educação (FNDE), a projetos educacionais que visem a formação continuada de professores e a aquisição de material didático. Os recursos para essas ações nos anos 2000 e 2001 foram destinados aos municípios com Índice de Desenvolvimento Humano (IDH) ${ }^{3}$ inferior a 0,5 . Os projetos de formação de professores apoiados devem visar à implementação do Referencial Curricular Nacional para a Educação Infantil, publicado pelo MEC em 1998. Esses projetos incluemse no programa do MEC denominado Parâmetros em Ação, principal ação da Secretaria de Educação Fundamental nos últimos anos.

No Quadro 3 são apresentados os dados da execução físico-financeira de todas as ações do Programa Atenção à Criança no ano de 2000. Verifica-se que as duas primeiras ações, executadas pela área de assistência social, somam $\mathrm{R} \$ 268.660 .000$, o que significa cerca de $9 \%$ do total do orçamento do Fundo Nacional de Assistência Social. Os demais programas, executados pela área de educação, totalizam $\mathrm{R} \$ 15.046 .000$, cerca de $0,1 \%$ dos recursos do Orçamento Federal para o setor educacional.

Ainda no âmbito do MEC/FNDE, a educação infantil é contemplada no Programa de Alimentação Escolar (antigo Merenda Escolar). Os recursos repassados aos municípios para a merenda escolar abrangem, entretanto, apenas as crianças das pré-escolas públicas e filantrópicas, ou seja, a faixa etária de 4 a 6 anos. Além de não ter uma cobertura para toda a educação infantil, o valor per capita ( $\mathrm{R} \$ 0,06 /$ dia letivo) é menos da metade do direcionado aos alunos do ensi-

${ }^{3} \mathrm{O}$ IDH é um indicador sintético de desenvolvimento humano, introduzido pelo Programa das Nações Unidas para o Desenvolvimento (PNUD) para acompanhar os avanços na situação socioeconômica de diferentes países. Inclui em seu cálculo dados de renda, de educação e de saúde. No Brasil, o índice tem sido calculado para estados e municípios e utilizado na definição de políticas e programas sociais. O valor do IDH varia de 0 a 1 . 
no fundamental público $(\mathrm{R} \$ 0,13)$. A estimativa é que, no ano 2000, os recursos do programa destinaramse a 3,8 milhões de crianças de pré-escola, o que significou um gasto aproximado de $\mathrm{R} \$ 45,6$ milhões.

Procurando-se avaliar os alcances e limites das políticas e programas federais destinados à criança de 0 a 6 anos, evidencia-se no âmbito das intenções de governo o crescente reconhecimento da importância da infância como fase do desenvolvimento humano, bem como dos direitos das crianças como cidadãs.

\section{Q uadro 3}

\section{Programa Atenção à Criança: Execução físico-financeira 2000}

\begin{tabular}{|l|c|c|}
\hline \multicolumn{1}{|c|}{ Ações } & \multicolumn{1}{|c|}{ Produto* } & $\begin{array}{c}\text { Recursos Liquidados } \\
\text { R\$1.000 }\end{array}$ \\
\hline Atendimento a crianças em creche & 1.620 .380 crianças atendidas & 258.073 \\
\hline Construção, ampliação e modernização de creche & & 10.587 \\
\hline Aquisição e distrbuição de materiadidático para EI & 274.825 módulos distribuídos & 5.372 \\
\hline Formação continuada de professores da EI & 2.683 professores capacitados & 3.415 \\
\hline Implementação do referencial curricular nacional para a EI & 13.565 professores capacitados & 5.315 \\
\hline Funcionamento da educação infantil & & 214 \\
\hline Assistência financeira para melhoria da educação infantil & & 730 \\
\hline TOTAL & & 283.706 \\
\hline
\end{tabular}

Fonte: Relatórios de Gestão da SEAS e do FNDE (produtos) e SIAFI/STN (Recursos liquidados).

* Em algumas ações, os dados sobre produtos não estavam disponíveis nas fontes analisadas.

EI = Educação Infantil.

Nota-se que grandes avanços no âmbito jurídico-legal vêm ocorrendo, especialmente após a Constituição de 1988, no que tange aos direitos da criança. O Estatuto da Criança e do Adolescente, de 1990, a Lei Orgânica da Assistência Social, de 1993, e a Lei de Diretrizes e Bases da Educação Nacional, de 1996, consagram tais avanços. Destacam-se, entre estes, o direito à educação da criança de 0 a 6 anos de idade, em creches e pré-escolas. Essas instituições passam a constituir a educação infantil, primeira etapa da educação básica.

Progressos também têm sido verificados na gestão governamental, com a descentralização políticoadministrativa e a participação da sociedade, especialmente no controle social das ações dos governos. A estruturação do Sistema Único de Saúde (SUS), a municipalização nas áreas de saúde, educação e assistência social, mesmo que em processo, respondem a esses parâmetros da Constituição. Das ações analisadas, várias têm mostrado avanço em sua gestão, como o observado no Programa de Alimentação Escolar, que, ao longo da década de 1990, passou por grande reformulação em seus processos de execução.
No caso da área da saúde, deve-se mencionar a instituição do repasse do Piso de Atenção Básica e a implementação do Programa Saúde da Família.

Ainda que venham se registrando alguns avanços também nas condições de vida das crianças no país, redundando, por exemplo, em significativa melhora nas taxas de mortalidade infantil, ainda há muito a se fazer para garantir à criança pequena um desenvolvimento integral adequado.

Observa-se que ainda é tímido o lugar ocupado pela criança com menos de 7 anos nas políticas públicas, apesar de ser esse o segmento populacional mais afetado pelas condições de pobreza e desigualdade. O percentual de crianças dessa faixa etária que vive em famílias com renda inferior a $1 \frac{1}{2}$ salário mínimo per capita chega a $42,2 \%$, bem superior ao mesmo índice na população em geral, conforme mostram os dados da Pesquisa Nacional por Amostragem de Domicílios (PNAD)4 de 1999.

\footnotetext{
${ }^{4}$ Pesquisa realizada pelo Instituto Brasileiro de Geografia e
} Estatística (IBGE) anualmente, exceto nos anos em que se realiza o Censo Demográfico. 
A situação é especialmente grave no caso da educação. Na verdade, a criança de 0 a 6 anos é quase ausente na política educacional do governo federal. Tal ausência é percebida, por exemplo, no Plano Plurianual 2000-2003, em que a educação infantil não apresenta sequer o status de programa, ao contrário dos outros níveis de ensino e até mesmo das modalidades de ensino. Evidencia-se, além disso, uma pronunciada fragmentação das ações destinadas à criança de 0 a 6 anos, mesmo no interior dos ministérios setoriais. A articulação entre as áreas é ainda mais precária, embora esforços possam ser identificados, como a criação do Comitê da Primeira Infância (CODIPI), em 2000, no âmbito do Programa Comunidade Ativa (antigo Comunidade Solidária).

Outro aspecto que demanda maiores investimentos diz respeito aos sistemas de informações gerenciais. Observa-se uma carência de dados sistematizados que permitam a formulação adequada de ações, bem como seu acompanhamento e avaliação.

Uma ausência também percebida diz respeito a processos efetivos de avaliação das ações. De um modo geral, não tem sido observado grandes esforços nessa direção. Algumas iniciativas merecem ser acompanhadas, como a avaliação sistemática da implementação e dos impactos do Bolsa-Alimentação, delineada pelo Ministério da Saúde.

Entre os limites e entraves para a oferta de serviços públicos de qualidade à criança pequena, provavelmente o mais importante diz respeito à formação dos recursos humanos envolvidos na operacionalização das ações. Em todas as três áreas analisadas educação, saúde e assistência social - esse problema se impõe e exige estratégias de solução. No caso da saúde, o Programa de Formação dos Profissionais de Enfermagem constitui uma importante iniciativa para minorar esse entrave.

Também no âmbito das equipes do governo federal, o qual é responsável pela normatização e coordenação das ações, verificam-se grandes carências relativas aos profissionais. As equipes são muito reduzidas e os técnicos freqüentemente têm contratos temporários de trabalho.
Os dados anteriormente apresentados restringemse às ações e aos recursos da União destinados à criança de 0 a 6 anos. Entretanto, a parcela dos gastos da esfera federal na área da educação básica é muito inferior àquelas assumidas pelos estados e municípios. Análises do gasto social consolidado, de todas as esferas de governo, realizadas no âmbito do Instituto de Pesquisas Econômicas Aplicadas (IPEA) para o ano de 1995 (Castro \& Fernandes, 1999), mostram que o Brasil gastou naquele ano $\mathrm{R} \$ 135,2$ bilhões com a área social, o que representou $22,1 \%$ do PIB; com educação foram gastos $\mathrm{R} \$ 27,2$ bilhões, sendo $47,7 \%$ pela esfera estadual, 27,3\% pelos municípios e 24,9\% pela União. Os gastos com educação representaram na esfera federal 8,4\% do gasto social; na instância estadual, 40,4\%; e na municipal, $32,9 \%$. A distribuição dos gastos segundo os níveis mostra que na instância federal a educação infantil representava $0,6 \%$ do gasto com educação; na esfera estadual, 4,3\%; e na municipal, $24,7 \%$. Infelizmente, estudos com a mesma metodologia para anos posteriores a 1995 não estão disponíveis.

O financiamento da educação infantil e a distribuição de encargos entre as diversas esferas de governo, atendendo ao artigo 30, inciso VI, da Constituição Federal, que atribui ao município a responsabilidade pela oferta dessa etapa da educação, com a cooperação técnica e financeira da União e do Estado, constitui uma questão de grande relevo para o tema proposto no presente trabalho. Visando contribuir com a discussão desse tópico, Castro e Barreto (2002) desenvolveram um estudo sobre os desafios impostos pelo Plano Nacional de Educação, comentado a seguir.

\section{Os desafios impostos pelo PNE: financiamento e gestão da educação infantil}

O estudo de Castro e Barreto (2002) aborda inicialmente as metas do Plano Nacional de Educação e utiliza aquelas referentes à expansão do atendimento para elaborar estimativas de demanda por matrículas na educação infantil e construir cenários dos impactos dessa expansão do atendimento sobre o financiamento dessa etapa educacional. 
Conforme lembram os autores, as 25 metas/objetivos para a educação infantil do PNE tratam da ampliação da oferta de creches e pré-escolas, da elaboração de padrões mínimos de qualidade de infraestrutura para o funcionamento adequado das instituições de educação infantil, da autorização de funcionamento dessas instituições, da formação dos profissionais da área, da garantia da alimentação escolar para as crianças atendidas nos estabelecimentos públicos e conveniados, do fornecimento de materiais adequados às faixas etárias, do estabelecimento de padrões de qualidade como referência para a supervisão, o controle, a avaliação e o aperfeiçoamento da educação infantil, entre outros aspectos.

Castro e Barreto (2002) reconhecem que todos esses objetivos e metas têm custo e, portanto, reflexos sobre o financiamento da área. Entretanto, dada a complexidade de abordar o impacto de todas elas, os autores destacam a que trata da ampliação da oferta, pelo seu inegável peso sobre os recursos financeiros necessários.

O objetivo/meta que representa o ponto de partida da análise é assim formulado no PNE: "Ampliar a oferta de educação infantil de forma a atender, em cinco anos, a $30 \%$ da população de até 3 anos de idade e $60 \%$ da população de 4 e 6 anos (ou 4 e 5 anos) e, até o final da década, alcançar a meta de $50 \%$ das crianças de 0 a 3 anos e $80 \%$ das de 4 e 5 anos" (Castro \& Barreto, 2002, p. 45). Castro e Barreto (2002) destacam que o estabelecimento de metas específicas para as duas faixas de idade ( 0 a 3 e 4 a 6 ) é justificada, no plano, pela história do atendimento a essas faixas etárias no Brasil, com o predomínio da área da assistência social para as crianças menores.

Mostram os autores que, segundo dados da Pesquisa Nacional por Amostragem de Domicílio (PNAD) de 1999, a taxa de freqüência à creche/pré-escola das crianças de 0 a 3 anos, no Brasil, era de cerca de $9,2 \%$. Para a faixa de 4 a 6 anos, a freqüência à creche/pré-escola era de $52,1 \%$, além de $8,1 \%$ que já se encontravam no ensino fundamental. Somadas, seriam 60,2\% das crianças de 4 a 6 anos já freqüentando escola em 1999. Considerando, portanto, os da- dos da PNAD-1999, concluem os autores que a meta do PNE para 2006, se tomada a faixa de 4 a 6 anos em todo o Brasil, já estaria alcançada ou próxima de ser atingida. No entanto, apontam que, para a faixa de 0 a 3 anos, cuja meta para 2006 é 30\%, há um enorme caminho a percorrer, pois a taxa de cobertura, segundo a PNAD-1999, não atinge 10\%.

Entretanto, a média nacional encobre uma pronunciada desigualdade nas taxas de atendimento nas diferentes unidades da Federação. Sendo um objetivo de ordem geral explicitado no PNE o de redução das desigualdades sociais e regionais no tocante ao acesso e à permanência, com sucesso, da criança e do adolescente na educação pública, concluem os autores que esse princípio também deve ser aplicado à educação infantil. Destacam que nessa etapa da educação básica a desigualdade de acesso é fortemente sentida, especialmente quando se considera a renda familiar das crianças atendidas. Se na classe de maior renda (acima de cinco salários mínimos per capita), conforme os dados da PNAD-1999, 32,5\% das crianças de 0 a 3 anos já freqüentam creche, na de menor renda (menos de $1 / 2$ salário mínimo) a cobertura não chega a 6\%. Das crianças de 4 a 6 anos de famílias de maior renda, cerca de $90 \%$ já freqüentam pré-escola ou ensino fundamental; para as de menor renda, esse percentual é de apenas $50 \%$.

A análise dos impactos financeiros do PNE realizada no estudo parte, portanto, do princípio de eqüidade regional explicitado no plano. Considera-se, assim, que a demanda pela educação infantil nos anos 2006 e 2011 resultaria dos percentuais do plano aplicados à população de cada estado (e Distrito Federal). No caso dos estados que já ultrapassaram a meta do PNE, manteve-se o mesmo nível de cobertura (resultado da divisão do número de matrículas pelo quantitativo da população na faixa etária) de 2000 . Por não haver projeções populacionais por unidade da Federação baseadas em dados recentes, utilizou-se nas estimativas da demanda a mesma população do ano 2000 (Castro \& Barreto, 2002)

Os resultados obtidos na análise da demanda, aplicando-se as taxas estabelecidas no PNE para 2006 
e 2011 à população de 2000 de cada estado, na faixa de 0 a 3 anos, levantada pelo Censo do IBGE, mostram que haveria aumento, para o Brasil, de mais de 3 milhões de matrículas até 2006, e, entre 2000 e 2011, crescimento de 5,7 milhões de matrículas.

Separou-se, no estudo, os dados das crianças de 4 a 5 anos daqueles referentes às de 6 anos, uma vez que o PNE prevê a inserção gradativa dessas crianças no ensino fundamental. Para as crianças de 4 a 5 anos, os percentuais utilizados foram $60 \%$ para 2006 e $80 \%$ para 2011. No que tange às crianças de 6 anos, considerou-se que, em 2006, $100 \%$ já estariam no sistema de ensino: $80 \%$ no ensino fundamental e $20 \%$ na préescola. Para 2011, estimou-se que 100\% freqüentariam o ensino fundamental. Os resultados encontrados indicaram que, para a faixa de 4 a 6 anos, em 2006, haveria um acréscimo de 1,4 milhões de matrículas; de 2000 a 2011, o aumento seria de cerca de 3,6 milhões.

Respondida, dentro dos limites da metodologia empregada, a pergunta "O que as metas de cobertura do PNE significam em termos de expansão da matrícula?", Castro e Barreto (2002) buscam investigar o impacto dessas metas sobre o financiamento da educação infantil. Como ponto de partida, é reconhecido que a análise da questão do financiamento público da educação infantil exige que se levem em conta os outros níveis e modalidades de ensino, uma vez que esses concorrem por recursos das mesmas fontes. Assim, procurou-se estimar as matrículas nos anos de 2006 e 2011 para os outros níveis e modalidades da educação, interpretando as metas do PNE e considerando as taxas de atendimento em 2000, calculadas pela razão entre matrículas e população por faixa etária.

Como o interesse do estudo recaía sobre o financiamento público, foi necessário subtrair as matrículas do setor privado. Trabalhou-se com a hipótese de que o alunado desse setor permaneceria constante no período 2000-2011. Também foram mantidas constantes a distribuição do alunado entre as instâncias estaduais e municipais. Com base nessas estimativas de demanda, Castro e Barreto (2002) constroem alguns cenários relativos aos recursos financeiros necessários à implementação do PNE.
A inexistência de estudos sobre os custos da oferta de educação com padrões de qualidade adequados, em seus diferentes níveis e modalidades, é um grande entrave para a análise das necessidades de financiamento das políticas. Desse modo, freqüentemente se usam dados dos gastos despendidos. Também no caso dos gastos, em virtude da organização da oferta da educação básica, em que os mesmos recursos materiais e humanos servem aos diferentes níveis e modalidades, é extremamente complexo depurar o gasto por aluno em cada um deles. É necessário, portanto, trabalhar com aproximações.

No estudo, Castro e Barreto (2002) calculam quanto cada estado e o conjunto de municípios de cada unidade da Federação teriam de recursos para a educação, considerando as receitas de impostos (dados do Ministério da Fazenda). Para determinar a capacidade de gasto associado à educação, no Brasil, admitem como hipótese que os diversos níveis de governo respeitem a imposição legal vigente no artigo $\mathrm{n}^{\circ} 212$ da Constituição Federal:

a) a União vincula à educação $18 \%$ dos recursos oriundos da receita de impostos federais a ela destinados;

b) os estados vinculam à educação $25 \%$ das receitas de impostos que arrecadam como também daquelas que lhe são transferidas;

c) os municípios vinculam à educação $25 \%$ das receitas de impostos que lhes são transferidas;

d) a União e os estados aplicam os recursos da contribuição social do salário-educação (quotas estadual e federal) segundo regulamentação vigente.

Com base nesses mínimos, são calculados os quantitativos de recursos das instâncias estaduais e o montante de todos os municípios de cada unidade da Federação para toda a educação. Em virtude da complexidade das questões vinculadas ao financiamento do ensino superior público, esse nível de ensino foi isolado no estudo citado, sendo os recursos efetivamente gastos em 2000 com esse segmento subtraídos 
dos gastos totais estimados, em cada instância analisada. ${ }^{5}$ Passa-se então a trabalhar com o restante, considerando-o como o gasto público mínimo estimado com a educação básica. Dividido esse gasto pelo número de matrículas em todos os níveis e modalidades da educação básica, chega-se a valores per capita médios para a educação básica para as instâncias estaduais e municipais de cada unidade da Federação no ano 2000. Os resultados assim obtidos mostram uma grande variação nesse per capita médio, com algumas unidades da Federação apresentando valores muito baixos (como Pará, Maranhão, Piauí, Ceará e Bahia).

Essa estimativa significa manter um mesmo valor per capita para todos os níveis e modalidades da educação básica, o que representa uma limitação do estudo, em razão, como apontado acima, da inexis- tência de dados sobre os custos reais de cada um desses níveis e modalidades. Porém, o estudo não tem a pretensão de resolver todas as questões envolvidas no financiamento da educação pública, apenas busca fazer uma aproximação ao tema.

Um primeiro cenário é construído pelos autores multiplicando-se, para cada estado, o valor per capita médio obtido pelo total de matrículas na educação infantil, no ano 2000. Somados todos os estados, chega-se a uma aproximação do gasto público total, no Brasil, que seria da ordem de $\mathrm{R} \$ 3,2$ bilhões com essa etapa da educação. Considerando-se as demandas calculadas para o PNE, já comentadas, seriam necessários $\mathrm{R} \$ 5,2$ bilhões no ano 2006 e $\mathrm{R} \$ 7,74$ bilhões em 2011, para o atendimento em creches e pré-escolas (Tabela 1). Isso significa um incremento de recursos

Tabela 1

\section{Comparação dos cenários para os gastos com educação infantil}

\begin{tabular}{lccc}
\multicolumn{1}{c}{ Cenários } & Estados & Municípios & Total \\
\hline A - Gasto público mínimo com Educação Infantil & & & \\
2000 & 310,0 & $2.960,8$ & $3.270,8$ \\
2006 & 496,3 & $4.751,6$ & 5247,9 \\
2011 & 655,7 & $7.090,3$ & $7.746,0$ \\
\hline B - Gasto público equalizado com Educação Infantil & & & \\
2000 & 310,0 & $2.960,8$ & $3.270,8$ \\
2006 & 575,2 & $5.562,6$ & $6.137,8$ \\
2011 & 874,3 & $8.181,0$ & $9.055,3$ \\
\hline B/A (em \%) & & & \\
2000 & - & - & - \\
2006 & 15,9 & 17,1 & 17,0 \\
2011 & 33,3 & 15,4 & 16,9 \\
\hline
\end{tabular}

Fonte: COTEPE, STN/MinFaz e PNE.

Elaboração: Jorge Abrahão de Castro, Francisco Sadeck e Angela Rabelo Barreto.

${ }^{5}$ A estratégia utilizada no estudo isola a questão da expansão da educação superior daquela referente à educação básica. Tratando-se de questão tão polêmica e complexa, ultrapassa as possibilidades de análise no âmbito desse artigo. De qualquer forma, para atender às metas do PNE para os vários níveis e modalidades de ensino, será necessário um aumento significativo de recursos destinados a cada um deles. O estudo aqui apresentado trata das necessidades de financiamento, e não das possibilidades de atendê-las. Se fosse esse o caso, seria mais comprometedor utilizar-se do artifício de isolar os níveis. 
da ordem de $60 \%$ em cinco anos e de $140 \%$ em 10 anos, tomando-se todo o Brasil.

A desigualdade observada nos resultados dos cálculos dos recursos per capita disponíveis nas diferentes unidades da Federação fortalecem a necessidade de que a instância federal atue no sentido de minimizálas, com formas consistentes de assistência financeira aos municípios, responsáveis pela oferta da educação infantil. Em um segundo cenário, Castro e Barreto (2002) tomam o valor estimado do gasto per capita médio na educação básica para o Brasil como sendo o valor mínimo, ou seja, os estados que apresentam per capita menor que a média teriam seus recursos complementados pelo governo federal. ${ }^{6}$ Nesse cenário de equalização mínima para os gastos seriam necessários, para a educação infantil, recursos públicos da ordem de R $\$ 6,1$ bilhões em 2006 e de R $\$ 9,1$ bilhões em 2011. Isso significa que a União deveria destinar cerca de 890 milhões de reais para a educação infantil no ano 2006 e mais de 1,3 bilhões em 2011.

Essas análises, ainda que limitadas pela ausência de dados reais e, portanto, baseadas em estimativas, evidenciam os desafios a enfrentar para a implementação das metas do PNE para a educação infantil. $O$ próprio PNE estabelece objetivos específicos relativos ao financiamento, os quais devem pautar a luta pela educação infantil. Seu cumprimento precisa ser buscado, o que implica a necessidade de criação de mecanismos de controle social. São eles:

20. Promover debates com a sociedade civil sobre o direito dos trabalhadores à assistência gratuita a seus filhos e dependentes em creches e pré-escolas, estabelecido no art. $7^{\circ}$, XXV, da Constituição Federal. Encaminhar ao Congresso Nacional um projeto de lei visando à regulamentação daquele dispositivo.

21. Assegurar que, em todos os municípios, além de outros recursos municipais, os $10 \%$ dos recursos de ma-

${ }^{6}$ Esse princípio do Fundo de Manutenção e Desenvolvimento do Ensino Fundamental e de Valorização do Magistério (FUNDEF) aplicado não apenas ao ensino fundamental mas a toda a educação básica. nutenção e desenvolvimento do ensino não vinculados ao FUNDEF sejam aplicados, prioritariamente, na educação infantil.

23. Realizar estudos sobre o custo da educação infantil com base nos parâmetros de qualidade, com vistas a melhorar a eficiência e garantir a generalização da qualidade do atendimento.

25. Exercer a ação supletiva da União e do Estado junto aos municípios que apresentem maiores necessidades técnicas e financeiras, nos termos dos arts. 30, VI e 211, § $1^{\circ}$, da Constituição Federal. (p. 48-49)

\section{Algumas considerações finais}

Os dois estudos utilizados nesse artigo, ambos realizados com a minha participação, evidenciam os grandes passos que necessitam ser dados para mudar a situação da educação infantil em nosso país. O primeiro, que aborda o lugar da criança de até 6 anos de idade e, especialmente da educação infantil, nas políticas públicas federais, mostra como tem sido tímida a participação da União na área. O segundo aponta os desafios, em termos de recursos, para a implementação das metas do PNE. Fica evidente nos dois a necessidade de dar cumprimento ao objetivo 25 do capítulo da educação infantil no PNE, o qual estabelece que a União e o estado devem exercer ação supletiva junto aos municípios que apresentem maiores necessidades técnicas e financeiras, nos termos dos arts. 30, VI, e 211, $\S 1^{\circ}$ da Constituição Federal.

No estudo de Barreto (2001), elaborado quando estava sendo formulado o Orçamento da União para o ano 2002, são apresentadas algumas sugestões para aquele orçamento e para revisão do PPA 2000-2003, ${ }^{7}$ as quais permitiriam implementar imediatamente algumas metas do PNE relativas à educação infantil. A primeira atenderia à meta/objetivo 12 , de garantir a alimentação escolar para as crianças atendidas na educação infantil, nos estabelecimentos públicos e

\footnotetext{
${ }^{7}$ Essas sugestões foram utilizadas pelo CODIPI em documento
} encaminhado por esse comitê aos ministérios econômicos por meio de parlamentares comprometidos com as políticas para a infância. 
conveniados, através da colaboração financeira da União e dos estados. Estimativas elaboradas pela autora para o repasse de um per capita de $\mathrm{R} \$ 0,13$ por aluno por dia letivo (o mesmo estipulado para o ensino fundamental público), incluindo todas as crianças matriculadas nas creches e pré-escolas públicas e conveniadas, mostravam que seriam necessários 116,6 milhões de reais, ou seja, 70 milhões a mais que o montante repassado em 2000 destinados à merenda dos alunos de préescola. $^{8}$

A segunda sugestão apresentada por Barreto (2001) seria de ampliação do apoio financeiro para aquisição de material didático (ação 3.008 do PPA) para todas as crianças matriculadas em creches e pré-escolas públicas e conveniadas. Nesse caso, utilizando-se o valor médio repassado de $\mathrm{R} \$ 68,01$ por aluno para os municípios com baixo IDH que se candidataram aos recursos do FNDE em 2000, a estimativa seria de um acréscimo de 316 milhões de reais no Orçamento na referida ação. ${ }^{9}$ Dessa forma, seria possível atender o objetivo 13 do PNE: assegurar, em todos os municípios, o fornecimento de materiais pedagógicos adequados às faixas etárias e às necessidades do trabalho educacional.

Outra sugestão aborda a necessidade de dar início ao cumprimento da meta cinco do PNE: estabelecer um Programa Nacional de Formação dos Profissionais de Educação Infantil que possibilitasse a habilitação dos professores e dirigentes das instituições que atuam na área. Aqui a proposta seria de articulação entre as três esferas de governo, sob a coordenação da União, uma vez que o ensino médio, incluindo a modalidade normal, está sob a responsabilidade dos estados, o superior, no qual se incluem

${ }^{8}$ A proposta do Poder Executivo para a merenda escolar no Orçamento 2002 era de 900 milhões de reais, incluindo ensino fundamental e pré-escolas.

${ }^{9}$ A proposta do Executivo para o Orçamento 2002 para essa ação era de apenas 5,3 milhões de reais. Se atendida a sugestão da autora, a assistência financeira da União na área da educação superaria os recursos previstos para a ação "Atendimento de crianças em creches", de responsabilidade da SEAS, de 251 milhões de reais. as licenciaturas, via de regra encontra-se no sistema federal e os professores e dirigentes a serem habilitados estão, em sua maioria, direta ou indiretamente vinculados à instância municipal. A possibilidade imediata apontada por Barreto (2001) seria de inserção de metas para o atendimento da demanda de formação dos profissionais leigos em programas como o de Educação de Jovens e Adultos, de responsabilidade do Ministério da Educação, e Qualificação do Trabalhador, gerido pelo Ministério do Trabalho, com recursos do Fundo de Amparo ao Trabalhador (FAT). Além disso, nas ações de formação continuada de professores de educação infantil, que vêm se destinando apenas à pré-escola, poderiam ser incluídos recursos para a estruturação do programa previsto no PNE.

As sugestões descritas levaram em conta a dificuldade de alterar, no momento em que foram apresentadas, a estrutura do PPA 2000-2003 e do Orçamento 2002. Por isso, todas elas tratam de inserção de novos recursos em programas e ações já previstos nesses instrumentos de planejamento. Mudanças mais profundas, entretanto, como a inclusão de um programa específico para a educação infantil no PPA, sob a responsabilidade do Ministério da Educação, foram também recomendadas em Barreto (2001).

Deve-se observar que as três sugestões apresentadas não levam em conta a expansão do atendimento, tratada posteriormente no estudo de Castro e Barreto (2002). Este estudo convergiria mais para a criação de um Fundo para a Manutenção e o Desenvolvimento da Educação Básica (FUNDEB), proposta que tem surgido como solução para o financiamento de todos os níveis e modalidades nela incluídos, e não apenas do ensino fundamental, como é o caso do FUNDEF.

As análises aqui apresentadas, ainda que não tratem de todos os aspectos envolvidos na questão do financiamento da educação infantil, evidenciam a complexidade do tema. Além disso, deve-se ter em mente que o financiamento é apenas um instrumento das políticas públicas, cuja formulação envolve muitos fatores, os quais ultrapassam os modestos objetivos do presente artigo. Vale, entretanto, comentar o fator que envolve o embate entre setores governamentais na divisão de responsabilidades e de recursos. Esse parece 
ser o caso vivido, no momento, no que tange ao apoio financeiro federal para a educação infantil. A continuidade do atendimento público e conveniado em creches e pré-escolas às crianças de famílias de baixa renda, que vem sendo financiado há quase três décadas pela área de Assistência Social, tem sido ameaçada pela compreensão de alguns dirigentes desta última de que, passando as creches a integrar os sistemas de ensino, não é mais atribuição da assistência social destinar recursos para esse atendimento. Daí a publicação da portaria nº 2.854/2000, da SEAS, já comentada.

A ausência de assistência financeira da União ao atendimento em creches e pré-escolas é um risco que as crianças de 0 a 6 anos e suas famílias não podem correr. É imprescindível que a questão seja resolvida e que se busque aplicar os princípios da integração horizontal das políticas, ou seja, a integração entre os diferentes setores governamentais que têm responsabilidades com a criança de 0 a 6 anos, além da integração vertical, isto é, entre as esferas federal, estadual e municipal. Não é demais lembrar a relevância da ação daqueles que fazem a defesa (advocacy) dos direitos da criança e, especialmente, do direito à educação infantil, para a solução de riscos como esse.

O tema proposto para o presente artigo - a educação infantil no contexto das políticas públicas - é muito amplo e poderia ensejar diferentes análises. Nele se buscou lidar com questões pertinentes ao financiamento e à gestão educacional. Tal análise, ainda que necessária para os que lutam pela expansão e melhoria da educação infantil, trata de temas freqüentemente considerados áridos e pouco interessantes. Espera-se, entretanto, que alguma contribuição advenha desta leitura, compensando o esforço dos leitores.

\section{ANGELA MARIA RABELO FERREIRA BARRETO, douto-}

randa do Instituto de Psicologia da Universidade de Brasília, é coordenadora técnica do Setor de Educação no Escritório da UNESCO no Brasil. Publicou: Educação infantil no Brasil: desafios colocados (Cadernos CEDES n ${ }^{\circ}$ 37: Grandes políticas para os pequenos Educação Infantil. Campinas: CEDES, 1995, p. 7-18); Professores do ensino de primeiro grau no Brasil: quem são, onde estão e quanto ganham (Estudos em Avaliação Educacional. São Paulo: Fundação
Carlos Chagas, jan.-jun. 1991); Situação atual da educação infantil no Brasil. (In: Subsídios para credenciamento e funcionamento de instituições de educação infantil. Brasília, MEC/SEF/DPE/COEDI, 1998, p. 23-35). Pesquisa atual: Crenças, Valores e Práticas de Professores de Educação Infantil.E-mail: amrfbarreto@uol.com.br

\section{Referências bibliográficas}

ALMEIDA, A.C.E., (2001). Ações governamentais destinadas à criança de zero a seis anos na área de assistência social Relatório. Brasília: IPEA.

BARRETO, A.M.R.F., (2001). Políticas e programas federais destinados à criança de zero a seis anos - Relatório. Brasília: IPEA

BARROS, E., (2001). Ações governamentais destinadas à criança de zero a seis anos na área de saúde e nutrição - Relatório preliminar. Brasília: IPEA.

BRASIL. Congresso Nacional, (1988). Constituição da República Federativa do Brasil. Brasília: Senado Federal.

, (1991). Estatuto da Criança e do Adolescente. Brasília. , (1993). Lei Orgânica da Assistência Social (LOAS). Lei $\mathrm{n}^{\circ} 8742$, de 7 de dezembro. Brasília.

(1996). Lei de Diretrizes e Bases da Educação Nacional. Lei no 9394, de 20 de dezembro. Brasília. , (1998). Avança Brasil: proposta de governo. Brasília. , (2000a). Secretaria de Estado de Assistência Social (SEAS). Portaria n 2.854 , de 19 de julho. Brasília.

Ministério do Planejamento, Gestão e Orçamento (2000b). Avança Brasil : Plano Plurianual 2000-2003. Brasília. (2001). Plano Nacional de Educação. Brasília: Senado Federal, UNESCO.

CAMPOS, M.M., ROSEMBERG, F., FERREIRA, I.M., (1993). Creches e pré-escolas no Brasil. São Paulo: Cortez.

CASTRO, J.A., BARRETO, A.M.R.F., (2002). Financiamento da educação infantil: alguns desafios e cenários para a implementação do Plano Nacional de Educação. Brasília: Senado Federal (mimeo.).

CASTRO, J.A., FERNANDES, M.A.C., (1999). Sistema de informações sobre os gastos públicos da área de educação (SIGPE): diagnóstico para 1995. Brasília: IPEA. TD 674.

VIEIRA, L.M.F., (1988). Mal necessário: creches no Departamento Nacional da Criança. Cadernos de Pesquisa, São Paulo, $\mathrm{n}^{\circ} 67$, p. 3-16.

Recebido em janeiro de 2003 Aprovado em julho de 2003 